\title{
Market digital platforms and economic inequality
}

\author{
M.V. Sukharev* \\ Karelian Research Centre of the Russian Academy of Sciences, Petrozavodsk, Russia
}

\begin{abstract}
The article studies the issues associated with the emergence and widespread distribution of such new systems for the market economy as global digital trading platforms, as well as their impact on economic inequality. The paper proposes the systematic analysis of the organization of these platforms, on the basis of which it is concluded that their main effect is associated with a significant reduction in transaction costs (by one or two orders of magnitude) when searching for goods, making transactions and paying for them. Statistics show an increase in economic inequality, though, a priori we could expect a reduction in inequality as a result of small and medium-sized businesses gaining access to global markets.
\end{abstract}

\section{Introduction}

The problems of economic and social inequality have been of concern to scientists and philosophers for many centuries. Socrates (the "Gorgias" dialogue) and Aristotle discussed these problems in the "Great Ethics". Modern authors [1,2,3] continue this research.

The general consensus is that both forced equalization and excessive inequality are harmful to social stability and to the rate of economic development. I.e. there must be an area of optimal inequality (the inverted U-shaped curve of S. Kuznets) in some point between these extremes. Modern studies cover the field of substantiating the Kuznets hypothesis on extensive statistical material from dozens of countries around the world, studying the cultural and economic features of inequality in different societies at different levels of development, and studying the institutional conditions for determining the distribution of inequality.

Just two or three decades ago, the distribution of benefits between people was established mainly as a result of social and market interactions within the institutional and market environment of a separate state. Until the 20th century, transaction costs for many goods established limits for the search for goods by the radius of walking or horse movement. In the 21 st century, globalization, the Internet, logistics networks and payment systems have radically changed the situation by creating such trading platforms as Amazon, eBay, AliExpress, and others.

Thanks to these systems, a small business or even an individual entrepreneur from a poor country, where labor and raw material prices are low, can enter the markets of rich countries with their product. If successful, these entrepreneurs (and, little later, their employees) can move to a higher social stratum in their country and even move to the middle class by the

\footnotetext{
* Corresponding author: suharev@narod.ru
} 
standards of developed countries, which reduces economic inequality both nationally and globally.

On the other hand, the creators and senior management of such trading platforms are joining the ranks of multibillionaires, increasing inequality. In large countries, trading platforms can change the distribution of wealth between people and regions by interacting between remote territories with different economic conditions.

An important aspect of the digitalization of world trade is the use of payment systems that begin to influence the global macroeconomics. Thanks to the automation of exchange, the use of national currencies is beginning to blur the boundaries between them. An ordinary Russian buyer pays for goods from China in rubles, without noticing how they are converted into yuan.

More broadly, the digitalization of markets is changing the global economy as a whole. The study of the impact of market-based digital platforms on economic inequality is of considerable interest to economic theory and government practice.

\section{Materials and Methods}

This article uses scientific publications, Internet sources (including aggregators of economic information), and websites of digital market platforms (DMP) as source materials.

The applicable method is a systematic and comparative analysis of economic concepts in relation to digital trading platforms in the modern economic literature, the study of analytical information on electronic commerce on the Internet.

Analysis of the number of definitions of the concept of "system" gives the following summary definition [4].

\section{A system is}

- a complex of interacting elements

- Due to the interaction between elements, the system forms integrity that has new (integral) properties and functions that the individual parts do not possess.

- The structure of interactions, relationships between elements, is of fundamental importance; the same elements, connected in different ways, can form systems with different properties.

- The interaction between elements has the character of MUTUAL interaction (what is called now "synergy" and is being studied by a new science - synergetics)

- The goals of the researcher are expressed to a certain extent in systems analysis. The study itself singles out a certain subsystem from the multitude of superimposed systems, which is the world.

Comparative analysis in economics "...moves to a new field. This new field splits the old idea that by comparing alternative economic systems, we can better understand how each one works... institutions vary radically and systematically from country to country. These differences and their significance for economic indicators are the subject of the new comparative economy" [5].

The Gini coefficient, a comparison of coefficients in different countries and its change over time [6] are used as an indicator of inequality.

\section{System-comparative analysis of digital market platforms}

The initial concepts should be clarified since the subject of research is a complex and heterogeneous system, including information, economic, institutional, and organizational components, and, moreover, rapidly developing (in the process of "formation"). 
V. Mesropyan's report [7] compiled a number of definitions of the concept of "digital platform" for platforms focused on serving markets. Summarizing these definitions, we can give the following comprehensive definition of a digital market platform (DMP): this is a digital system of interaction in the market, a business model that facilitates exchanges between participants (producers and consumers), ensuring mutually beneficial trade. The DMP provides an open infrastructure for participants and establishes new algorithmic rules for interaction that reduce transaction costs and change the division of labor.

The DMP participants include the following four main types: owners of the platform, managers (providers), complementors (DMP developers), and end independent users (consumers, suppliers, etc.) [8]

The IMF working papers provide the following wording: "... digital intermediary platforms that charge fees can be defined as online interfaces that facilitate direct interaction between multiple buyers and multiple sellers, while the platform does not assume ownership of the goods or services being sold (indirectly).

In turn, since digital intermediary platforms can also provide other services, digital intermediary platform services (for a fee) are defined as online intermediary services that allow transactions between multiple buyers and multiple sellers, while the platform performing the intermediary services does not assume ownership of the goods or the provision of services that are sold (through intermediaries)." [9]

The conceptual structure of the DMP is also proposed there (Fig. 1).

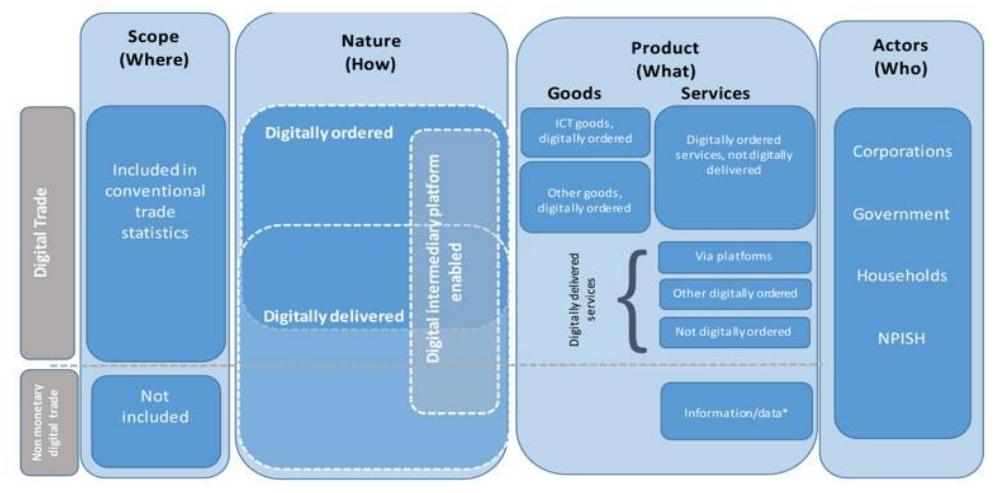

Fig. 1. The conceptual structure of digital commerce. Source: [9].

This concept includes paid and non-monetary (free for users, usually based on advertising) DMP, recorded and unaccounted for by statistics, tangible (but digitally ordered) and digital products, goods and services delivered over networks, as well as participants: corporations, authorities, households and non-profit organizations.

The analysis of a number of works on the problem of e-commerce $[9,10,11,12,13,14,15]$ as well as the practice of leading DMP (Amazon, AliExpress, eBay, etc.) using a systematic and comparative analysis allows us to formulate the following principles of their structure and operation:

- DMPs are built on the global Internet information network. The most important features of this network:

- messages are almost instantaneous (the global latency measured by the Ping utility is 3050 milliseconds and rarely exceeds 200 milliseconds)

- the cost of transmitting digital and alphabetic information is negligible

- duplex packet transmission of information with addressing sender-receiver (as opposed to radio, where the station broadcasts in one direction to an indefinite range of recipients) 
- the possibility of reliable protection of communication due to encryption of messages from addressee to addressee

- the network and network-based DMPs allow direct two-way communication between the seller and the buyer

- the memory capacity of the servers serving the DMP allows storing an almost unlimited number of product descriptions, including text, digital, and graphic (up to dozens of highresolution photos)

- servers provide the ability to search for the necessary products by keywords, and the most developed (for example, Yandex.Market) by filters specific to product groups (for example, screen size and resolution, memory capacity, price range, etc. for smartphones); complex technical products can use dozens of filters

- these features of DMPs dramatically (tens or even hundreds of times) reduce the transaction costs of finding the best product at the global level

- DMPs are either equipped with interfaces with existing payment systems or use their own interfaces; usually, they provide the ability to use many systems that are convenient for different users, these are credit and debit cards Visa, MasterCard, systems such as PayPal, Qiwi, etc. From an economic point of view, they are not money, they are prepaid cards and wallets, funds for which are contributed by fiduciary (government) money. But during their existence, they have achieved the ability to convert currencies, which is crucial in cross-border trade.

- Thanks to the progress of payment systems, the buyer can instantly pay for the goods anywhere in the world, avoiding visits to banks and exchange offices.

- DMPs either create their own global logistics networks or enter into long-term contracts with existing ones, most often giving the buyer the opportunity to choose between several networks; the essence of the matter is to deliver material goods from one point of the planet to any other (including from small enterprises or even individual entrepreneurs)

- Many DMPs provide an opportunity for buyers to leave their feedback on purchased goods, which makes it easier for the next buyer to choose both in terms of product selection and in terms of suppliers.

- Some DMPs (for example, AliExpress) provide the buyer with the opportunity to open a dispute over the execution of an order and provide their evidence (screen shots, photos of defective products). Due to the fact that half of the world's population has smartphones, it is thousands of times faster and cheaper than photographing goods on film, developing, printing on photo paper, and sending a paper photo by mail.

\section{Features of real DMPs operation}

The DMP structure, rules, and built-in algorithms for participation (forms for sellers and buyers, product classification, search methods, etc.) are very similar, but there are also important differences. For example, eBay only provides a trading platform, and on AliExpress, the seller receives money for the order only after the buyer confirms receipt of the parcel.

Yandex.Market has a much more developed product selection system than even such world leaders as AliExpress or Amazon.

Further information from the review [16]. 
Amazon has 14 marketplaces worldwide; eBay has 23 global sites. More than 197 million visitors from all over the world visit Amazon every month. This is more than 2.3 billion visitors in 12 months.

There are over 180 million active buyers and about 2 billion daily transactions on eBay DMP. More than half of eBay's annual sales revenue comes from 60 million customers outside the United States. Demographically, Amazon's customers tend to be more affluent. Research shows that the average Amazon shopper is between the ages of 45 and 54, is married, has children, and has a college degree.

Among eBay users, $57 \%$ are men and $43 \%$ are women. The largest group - 32\% - are buyers aged $35-49$ years.

eBay includes an auction system where buyers can bid higher prices for hard-to-find items. In contrast, prices on Amazon are fixed. Typically, eBay charges a flat fee of $10 \%$ per sale (it depends on the category), but this does not include a fee for processing payments via PayPal. Usually, it costs an additional 2.9\% + 20p. Amazon charges a standard $15 \%$ fee, which also includes a payment processing fee.

The distribution among the world's largest DMPs by trade volume in 2019 is shown in F

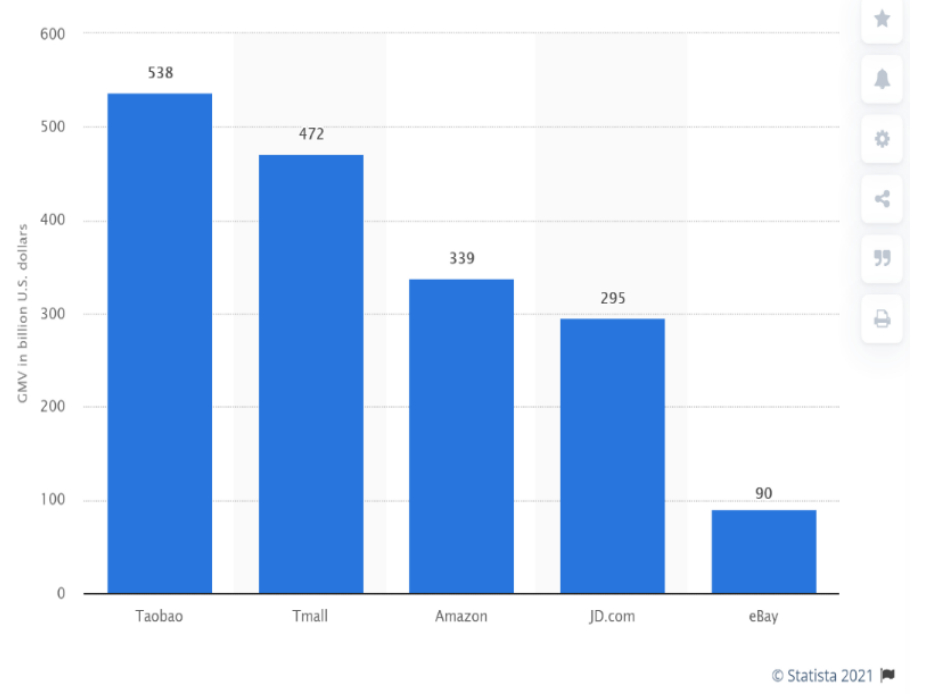

Fig. 2. The most popular online marketplaces in the world in 2019 by gross merchandise value (in billions of US dollars). Source: https://www.statista.com/statistics/885354/top-global-onlinemarketplaces-by-gmv/.Table 2 . Shows the distribution of consumers by product type and country of the world.

Table 2. Share of consumers who bought a product type on foreign e-commerce sites (percentage) Source: [14].

\begin{tabular}{|l|l|l|l|l|l|l|}
\hline Product type & Australia & China & Japan & Russia & England & USA \\
\hline Fashion & 40 & 36 & 20 & 51 & 32 & 31 \\
\hline Electronics & & & & & & \\
\hline $\begin{array}{l}\text { Computer } \\
\text { electronics }\end{array}$ & 21 & 14 & 12 & 18 & 11 & 16 \\
\hline $\begin{array}{l}\text { Household } \\
\text { appliances }\end{array}$ & 10 & 13 & 6 & 17 & 6 & 6 \\
\hline Cell phones & 9 & 12 & 3 & 17 & 6 & 8 \\
\hline
\end{tabular}


Table 2. Continued.

\begin{tabular}{|l|l|l|l|l|l|l|}
\hline $\begin{array}{l}\text { Digital } \\
\text { cameras and } \\
\text { audio } \\
\text { devices }\end{array}$ & 13 & 19 & 5 & 8 & 7 & 8 \\
\hline $\begin{array}{l}\text { Print, } \\
\text { publishing } \\
\text { and media }\end{array}$ & 43 & 13 & 27 & 9 & 29 & 22 \\
\hline $\begin{array}{l}\text { Beauty and } \\
\text { cosmetics }\end{array}$ & 19 & 42 & 21 & 21 & 15 & 14 \\
\hline Toys & 16 & 8 & 7 & 20 & 12 & 15 \\
\hline $\begin{array}{l}\text { Home and } \\
\text { furniture }\end{array}$ & 14 & 7 & 8 & 17 & 8 & 11 \\
\hline Food & 7 & 35 & 14 & 5 & 6 & 9 \\
\hline $\begin{array}{l}\text { Gifts and } \\
\text { flowers }\end{array}$ & 11 & 6 & 4 & 7 & 10 & 9 \\
\hline $\begin{array}{l}\text { Sporting } \\
\text { goods }\end{array}$ & 11 & 8 & 7 & 9 & 4 & 6 \\
\hline $\begin{array}{l}\text { Spare car } \\
\text { parts }\end{array}$ & 9 & 3 & 3 & 10 & 5 & 7 \\
\hline $\begin{array}{l}\text { Home \& } \\
\text { Gardening } \\
\text { Tools }\end{array}$ & 7 & 5 & 4 & 9 & 5 & 7 \\
\hline
\end{tabular}

Figure 3 shows the change in the Gini coefficient in China in recent years. China is chosen because, firstly, it has the highest growth dynamics among the largest economies in the world, and secondly, it has the fastest and most extensive development of cross-border digital trade, and it is focused on bringing small and medium-sized businesses to world markets. Interesting fact that this ratio rises (stratification increases) during periods of rapid economic growth, and falls when growth rates decline. Digital platforms do not yet have a noticeable impact on the economic stratification at the country level.

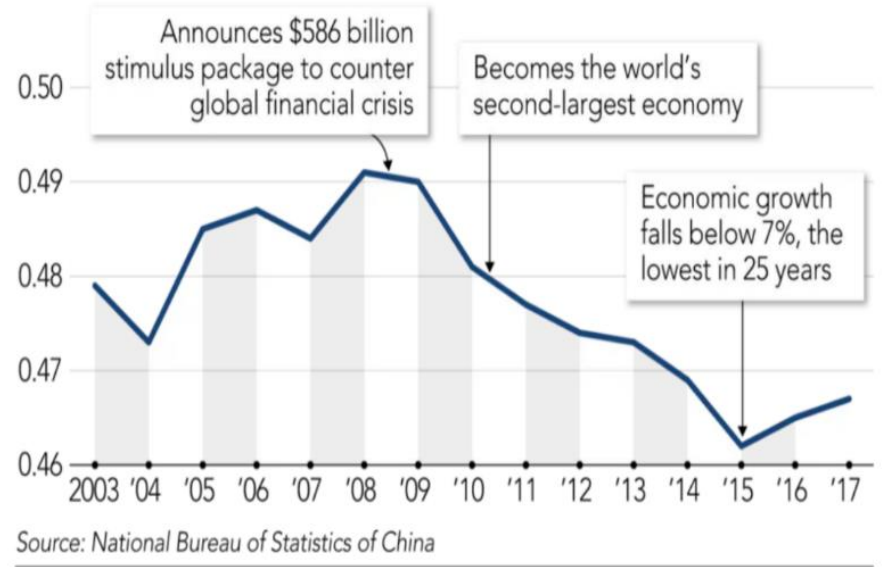

Fig. 3. Source: Nikkey Asia. https://asia.nikkei.com/Spotlight/Asia-Insight/China-s-tech-boom-leaveswide-rich-poor-chasm. 


\section{Results and Discussion}

- The analysis of the materials presented in the articles and other sources on the issues of electronic commerce, as well as the practice of leading DMPs using a systematic and comparative analysis allows us to formulate the following basic theoretical assumptions:

- Today, digital market platforms are the most important engine of fundamental changes in the global market.

- The growth of trading volumes on these platforms is three to five times faster than the overall growth of the markets and is not decreasing yet.

- The main economic reasons for this growth are lower transaction costs in digital markets compared to conventional ones, as well as increased competition due to the expansion of markets to the territory of the entire Earth.

- Economic inequality under the influence of accelerated development, an important factor stimulated by DMPs, initially increases, however, with a decrease in growth rates as a result of overheating of the economy, it decreases, returning to a civilizationally conditioned norm.

\section{Conclusions}

Most of the world's markets will become digital over the coming decades. This will affect the economies of all countries and regions within the country. The study of market digitalization processes is therefore of great scientific and practical importance.

\section{Acknowledgements}

The study was carried out within the state task of the Karelian Research Centre of the Russian Academy of Sciences on the topic "Institutions and Social Inequality in the Context of Global Challenges and Regional Constraints".

\section{References}

1. D. Castells-Quintana, V. Royuela, The annals of regional science, 52, 343 (2014)

2. F. Bourguignon, F. H. G. Ferreira, M. Walton, The J. of Economic Inequality, 5(2), 235 (2007)

3. M.V. Sukharev, Modern Control Technologies, 3(93), 9309

4. T.V. Morozova, G. B. Kozyreva, M.V. Sukharev, The Region as a Socio-Economic System, 308 (2009)

5. S. Djankov, E. Glaeser, Rafael La Porta, F. Lopez-de-Silanes, A. Shleifer, J. of Comparative Economics, 31(4), 595 (2003)

6. G. L. Gromyko, I. N. Matyukhina, Statistics Issues, 9, 56 (2015)

7. Digital platforms became the new market power, https://www.econ.msu.ru

8. I. Z. Geliskhanov, T. N. Yudina, A.V. Babkin, Economic Sciences, 11(6), 22 (2018)

9. How to Move Forward on Measuring Digital Trade, https://www.imf.org

10. D. P. Byrne, L. A. Martin, Int. J. of Industrial Organization

11. J. N. Inekwea, Y. Jinb, M. R. Valenzuela, Emerging Markets Review, 37, 134 (2018) 
12. A. Lapatinas, Economics Letters, 174, 35 (2019)

13. G. Steel, Geoforum, 120, 22 (2021)

14. Studies in Trade, Investment and Innovation, 91, 2019

15. T. Wang, G. C. Wright, J. of Economic Theory, 189 (2020)

16. C. Dunne, eBay vs Amazon - The Complete Comparison Guide (2021) 